\title{
For What It's Worth: An Introduction to Valuation Studies
}

\author{
Claes-Fredrik Helgesson and Fabian Muniesa
}

Welcome to Valuation Studies! We are very glad that you have set your eyes on the very first editorial of this new journal. The aim of this inaugural editorial is manifold. We aim, firstly, to provide some reflections about the starting of this journal. This will bring us both to the issue of the perceived topicality of the study of valuation as a social practice as well as our provisional answers to the many questions embedded in the very embarking on such an endeavour. (Why a new journal? Why open access? Why a transdisciplinary scope? Etc.)

Secondly, we want to take the opportunity to discuss what we take as the scope of the journal. We feel that the topic of valuation as a social practice would benefit from a large amount of openness. Yet, there are also limits to the amount of diversity that can be fruitfully embraced within the (digital) covers of any journal.

Thirdly, we would also like to address the many questions concerning valuation of academic work that relentlessly surface in an endeavour such as this one. (Will the contributions be any good? Will the journal provide a good arena for scholarly discussions about valuation and the study of it? Will an article published in Valuation Studies given any value in the valuation practices performed by the universities to evaluate faculty and candidates for positions? Etc.) Finally, we would want to touch upon the issue of further actions, ours as well as of others.

Claes-Fredrik Helgesson, Department of Thematic Studies - Technology and Social Change, Linköping University, claes-fredrik.helgesson@liu.se

Fabian Muniesa, Centre de Sociologie de l'Innovation, Mines ParisTech, fabian.muniesa@mines-paristech.fr

(C) 2013 Claes-Fredrik Helgesson and Fabian Muniesa LiU

Electronic Press, DOI 10.3384/vs.2001-5992.13111

http://valuationstudies.liu.se 


\section{On the Topicality of Valuation}

Valuations appear to be performed almost everywhere. Countries, restaurants, schoolchildren, damages, pets, waste and indeed academics, appear all to be subject to a wide variety of valuations to assess such things as creditworthiness, performance, aesthetics, or return on investment.

Turning to popular culture and the world of cinema we can learn that the movie Moneyball, to take one example, in the opening weekend in the US grossed $\$ 19.5$ million. ${ }^{1}$ (The same source reports first weekend ticket sales of $\$ 16,800$ in Sweden and $\$ 539,000$ in France. Presumably, though, in other currencies than USD.) The movie furthermore received six Oscar nominations, among them the one for best picture and best adapted screenplay. None of the nominations were translated into an award, but, as we know, a nomination is in itself treated as a valuation signifying a value to those being nominated. In addition, Moneyball appeared on a number of US critics' top ten lists for best movies of $2011 . .^{2}$ According to the site $\mathrm{IMDb}^{3}$, the movie has an 87 of 100 metascore of critics, and 125,000 users have on the same site produced a 7.6 average rating on a scale from one to ten. Turning to the movies provides a telling illustration of the propensity in current society to gauge things, assess them, rate them, put monetary value on them and so on. In short, valuation appears to be an engaging social practice.

There is something with the topic of the movie Moneyball as well. The movie depicts the story of how a general manager of the baseball team Oakland Athletics together with a young economics graduate tries out new ways to use statistics to value players. The aim is to deviate from the established practices to raise the poor team's sportive performance above what it's budget normally would allow for. In short, the main plot concerns the experimentation with new valuation practices to perform better on the baseball field. Also, it depicts how much of the social ordering in baseball, not the least including the practices of the scouts and the coach, was ingrained with the traditional ways to value baseball players. The movie thus provides a suggestive illustration of how both the outcomes of valuations might have re-ordering effects, and how the making of the valuations performs certain orders that needs to change if the way of doing the valuations is to change. The new valuation practices translated into contracting other players, and the new valuation practices entailed a transformation in how scouting for new players was performed, and by whom.

\footnotetext{
${ }^{1} \mathrm{http}: / /$ boxofficemojo.com, accessed 25 October 2012.

2 http://www.imdb.com/title/tt1210166/, accessed 25 October 2012.

${ }^{3}$ International Movie Data-base.
} 
Moneyball might be a bit of an exception among movies in how the plot foregrounds valuation as a social practice. Yet, we would argue, it is indeed a challenge these days to find areas where there are no valuation practices whatsoever going on. Movie stars, to stay and further add to the cinematic theme, have, for instance, been subject to statistical assessments linking their worth to the rental income of their past movies (cf. Wallace, Seigerman, and Holbrook 1993). Wherever we set our eyes, there appear to be a plethora of valuations going on at the same time. Most things are, it appears, subject to a complex matrix of valuations. These valuations are, moreover, often performed by highly complex socio-technical orderings involving several actors and instruments. (Think of the practices related to the grading of pupils in education to highlight one such highly complex valuation practice.)

For those a bit daring, there might actually even be a potential party game here. Drawing cards with random words (nouns or verbs presumably), contenders could be tasked to name distinctively different practices of valuation that currently are in place focusing on the referred object. The contender making the longest list would be the winner (and would be the one that most exhaustively substantiated our point about the proliferation of valuation as a social practice). ${ }^{4}$

The various valuations carried out do also regularly matter. Some choose what movie to watch based on critics reviews, and others might look at the first weekend ticket sales for the same purpose. Valuations of creditworthiness regularly translate into interest rates (Poon 2009), the valuation of the worth of damaged nature might translate into economic damages (Fourcade 2011), and the valuation of academics might translate into who gets research grants or attractive positions (Lamont 2009). The performance of valuations are thus not only ubiquitous; their outcomes participate in the ordering of society.

\section{Why a Journal?}

There is a variety of scholarly work merging on the topic of valuation in various forms. This work furthermore appears in many places and in many guises in the interface of a variety of approaches from several disciplines such as sociology, economic sociology, science and technology studies, management and organisation studies, social and cultural anthropology, history, market studies, institutional perspectives in economics, accounting studies, cultural geography, philosophy, and literary studies. It is our view (or perhaps hunch) that this work would benefit from a good amalgamating arena that facilitates dialogue and debate between different scholars of different approaches and disciplines. That was what made us contemplate

${ }^{4}$ The curious might want to learn that bingo today is the highest ranked party game at the site boardgamegeek.com [http://boardgamegeek.com/partygames/browse/ boardgame?sort=rank\&sortdir=desc, accessed 12 November 2012] 
starting Valuation Studies. Our perception was further substantiated by a recent review article, where Michèle Lamont identified no less than eight different literatures related to sociology alone that "concerned with how value is produced, diffused, assessed, and institutionalized across a range of settings" (Lamont 2012, 203). Furthermore, she notes that these literatures thus far "have not been in a systematic dialogue with one another" (ibid., 204).

The aim of the journal is therefore plainly to be a hub for work from the variety of disciplines and approaches that are related to the study of valuation as a social practice. Specifically the journal will provide a space that allows for dialogue and debate about this topical topic. We therefore envision the duality of a focused scope on valuation as a topic, while fostering a broad scope as to what kind of valuations are empirically examined or indeed how valuations are approached theoretically and methodologically. A slight majority of the thus far submitted contributions are in the realm where economic aspects are central to the valuation practices examined. This is all fine and very welcome. We will, however, encourage and make efforts to make Valuation Studies a site with a scope as broad as possible when it comes to the valuation practices under scrutiny.

\section{Challenges to the Study of Valuation}

Stating that "valuation as a social practice" is a specific and interesting topic to study brings on several challenges. Valuation has many objects as well as many subjects, and is a process that takes many forms. Sometimes it is about assessing value, sometimes about producing it, and sometimes about both at the same time. Finally, valuation might be appreciated and analysed in many ways. This is both a blessing and a curse when claiming that "valuation studies" is an emerging field that is possibly identifiable. State it broadly, and valuation becomes everything and its study meets the entire field of the social sciences and humanities. State it narrowly, and the study of valuation as a social practice becomes the business of a handful of contributions locked up inside a closed and abstruse field of inquiry.

It is clear that we, within this journal, want to work with a broad, inclusive, and malleable scope that brings contributions in conversation with one another, a conversation that would have been harder or more unlikely in other outlets. We need, for sure, lines of demarcation: some studies are clearly not studies that take "valuation as a social practice" as their main topic of inquiry. Below, we will provide some tentative lines of demarcation of the scope. We also have to acknowledge that such a task is most productively done in broad collectives. That is one reason why we are so happy with the contributions made by members of the advisory and editorial boards of the journal under the guidance of Hans Kjellberg and Alexandre Mallard (Kjellberg et al. 2013). What we might mean with valuation 
and how we might approach and study it, and with what questions, are also topics that we hope could nurture interesting discussions and debates on the pages of this journal.

One interesting challenge regarding what we might mean with valuation emerged early in this work and relates to the question of languages. Barbara Czarniawska, a member of the editorial board, approached us in e-mails about the polysemy of the notion of valuation, and specifically the possible differences in polysemy between different languages. Drawing on her Polish mother tongue she illustrated it:

In Polish, there are two different verbs: one (wyceniać) means "to price", the other (wartościować) "to valuate", the latter very clearly a qualitative endeavour. To wit, one would say: "you must price the value of the diamond you inherited", indicating that these are two different things. . . . Further, there is a word, "waluta" (currency), which is a clear loan from Latin, but has no linguistic connection to "cena" (price) or "wartość" (value). But then, the root "cena" is the basis of the word "to appreciate" (cenić), with a semantic, not linguistic, connection to Latin (in contemporary Italian "apprezzare", which comes from “prezzo", price). 5

In Swedish, the noun for valuation ("värdering") change face when put in the plural ("värderingar"). It then comes to also signify values or norms in the plural rather than only valuations in the plural. It is as if to remind of an intimate connection between valuations and values, without spelling it out. For the French, the distinction is quite strong between "valoriser" and "évaluer", but the usual mixtures of meanings do also apply. The article by Francois Vatin in this first issue is precisely a discussion on these lines, as regards these French terms (Vatin 2013). David Stark introduced his reflection on value with a similar exploration on the meanders of the Germanic vocabulary of worth (Stark 2009).

To these reflections on the differences between languages, one can bring John Dewey's:

[W] hen attention is confined to the usage of the verb 'to value', we find that common speech exhibits a double usage. For a glance at the dictionary will show that in ordinary speech the words 'valuing' and 'valuation' are verbally employed to designate both prizing, in the sense of holding precious, dear (and various other nearly equivalent activities, like honouring, regarding highly) and appraising in the sense of putting a value upon, assigning value to. This is an activity of rating, an act that involves comparison, as is explicit, for example, in appraisals in money terms of goods and services. The double meaning is significant because there is implicit in it one of the basic issues regarding valuation. For in prizing, emphasis falls upon something having definite personal reference, which, like all activities of distinctively personal reference, has an

5 Email correspondence from Barbara Czarniawska to the editors of Valuation Studies, 9 August 2012. 
aspectual quality called emotional. Valuation as appraisal, however, is primarily concerned with a relational property of objects so that an intellectual aspect is uppermost of the same general sort that is found in 'estimate' as distinguished from the personal-emotional word 'esteem.' That the same verb is employed in both senses suggests the problem of upon which schools are divided in the present time. Which of the two references is basic in its implications? Are the two activities separate or are they complementary? In connection with etymological history, it is suggestive (though, of course, in no way conclusive) that 'praise,' 'prize,' and 'price' are all derived from the same Latin word; that 'appreciate' and 'appraise' were once used interchangeably; and that 'dear' is still used as equivalent both to 'precious' and to 'costly' in monetary price. (Dewey 1939, 56)

There are thus interesting shifts of signification of valuation that are both challenging for, and useful to, the study of what we could take as practices of valuation. One feature appears to recur, and that is the one between the variable presence or absence of economic registers of worth when specifying what valuation stands for. Valuation might both denote something like the establishing of a monetary price for the sale of a book and the non-monetary assessment of the academic quality of a scholarly journal article. This flexibility of the notion is unequivocally central for this journal since it allows for interesting juxtapositions of studies of different phenomena. It also opens for examination precisely the concurrent co-existence of different valuations, much as Viviana Zelizer explored the multifaceted concurrent economic and affective aspects of intimate relations (Zelizer 2005).

\section{Is Value Socially Constructed? A Few Hints}

Of course, it is quite obvious that a call for studying valuation "as a social practice" means dealing with the problem of social construction, a problem that contributing authors are expected to stumble upon. A few candid questions can be asked in this regard, and a few provisional answers to engage with discussion can be provided.

Is value a social construction? The general agreement is that the answer to that question is: Yes, quite. But it is sometimes unclear what "social construction" means, and social-scientific debate on this is far from closed. The sense of this expression is often associated, in the social sciences, with an idea of something being the outcome of a shared belief: value exists because people think it does. But take a bridge over the river: it is a construction-and quite a social one insofar as it is the outcome of organized social work. This idea of social construction, quite different than the preceding one, could very well be applied to value: value is then seen as the outcome of a process of social work and the result of a wide range of activities (from production and combination to circulation and assessment) that aim at making things valuable. 
Is value objective, then? Of course it can be-as soon as it undergoes a felicitous process of objectification. If valuation studies can learn something crucial from the tradition of science studies, it is precisely to take objectivity seriously, that is, as a very demanding business, historically contingent and materially consequential (Daston and Galison 2007). What counts (and should be investigated as such) is what makes valuation solid or weak, meaningful or flawed, useful or useless in particular situations. What counts are the contingent circumstances that allow, sometimes, for the construction of the objectivity of value.

Is value subjective, then? Well, it is too, in a way. But what shall this mean? Valuation is indeed tied to the conditions of desire and desirability, to the entanglements that are created between people and things, and between people themselves-to "values" too, as standard sociology would have it. And those entanglements constitute a most suitable topic for valuation studies. But this would barely translate into a simple idea of the value of things being just about the confluence of "wants" as in the so-called liberal theory of value. Of course, one may find empirical situations in which subjectivity is indeed reduced to a scheme of consumer preferences. But a more refined view of subjectivity is generally in order, one attentive to the shifts of agency and the transformations of consciousness that are at work in processes of attachment and detachment.

So do people have several values? Yes-except that "to have values" is indeed a practical process, not some kind of a natural state. Caution, in particular, with the constructive effects that methodologies for the elicitation of values do have is of particular relevance to valuation studies. Valuation studies operate indeed in the realm of reflexive modernity. It should also be noted that the classification of several regimes of value or the establishment of different patterns of valuation has been, for decades, an acknowledged ambition of the sociological and anthropological old school. We are definitely aiming for something newer and beyond that here.

And do things have several values? Yes, what things are worth can be manifold and change-and these values can be conflicting or not, overlapping or not, combine with each other, contradict each other. All, or almost all, depends on the situation of valuation, its purpose, and its means. Broad segmentations such as the distinction between "economic" and "non-economic" value can make sense at some level, only the devil is in the detail. Something valued as a financial asset, for example, can be valued differently by different accountants or different investors. And then this thing can be valued in an entirely different way in other circumstances (i.e., not as financial asset, but as a political project, as personal property, you name it). 


\section{Valuation Studies in the Valuation Metrics of Academic Work}

Valuation Studies is also itself embedded in the practices of valuation that characterises academic life. First, we rely on the same review process with double-blind reviewing of journal articles, as do many credible academic journals these days. This is a convention, of course, and perhaps some alternative ways of reviewing should be explored in the future. In this we want to make the review process as valuable as possible to all parties involved in this (non-reimbursed) work of valuation. Secondly, as an academic journal we are unavoidably caught in the multitude of valuation practices that take place in academia. This involves also the indexing of journals (where a journal is indexed is sometimes taken as an indicator of the quality of its content).

When discussing the Valuation Studies venture with colleagues, one of the recurrent topics is precisely the rating or ranking of the journal. As a new venture, Valuation Studies is naturally not ranked. It is, as we like to say, in the strange state of being unranked that it shares with other luxury products. We realise, of course, that such arguments might not carry much weight in research assessment exercises or in appointment committee meetings, that is, in settings where the valuation practices truly can have reordering effects in academia. We will, to that effect take great pains in getting the journal recognised where it needs to be recognised. It is also here where the format of open access is helpful. The ease by which texts in Valuation Studies can be disseminated will facilitate them being read, provided, of course, that the content we as a collective put on those pages is valuable. Being read and being in conversation with others do carry weight in valuations and is something we will strive to facilitate in the operation of this journal.

\section{The Worth of the Pudding Lies in the Conversations}

Ending the inaugural editorial is just the beginning. The worth of the venture to start a new journal has to be assessed in how it engages to create new conversations and new ideas. The test, then, lies in the ability of Valuation Studies to do exactly that. We do, to this effect, want to encourage whoever thus inclined to join in. Manuscripts are welcome and we are looking for traditional journal articles as well as short opinion pieces or research notes, interviews, staged debates, or indeed longer than normal journal articles. To join in, also implies participating in the review of manuscripts considered for the journal as well as reading, (ap)praising, debating, and citing the published contributions. For what it's worth, let's talk! 
Acknowledgements. Starting a new journal is a truly collective endeavour. Many have shared the work that now has made the first issue possible and we would like to acknowledge their contributions. The members of the editorial office at Technology and Social Change, Linköping University, Lotta Björklund Larsen, Karin Thoresson, Maria Eidenskog, and Josefin Frilund have been invaluable in finding out various aspects in how to make a new journal and then execute on these. Thanks! The contributors to the first issue have been invaluable in providing their manuscripts to such an untested outlet as Valuation Studies. The anonymous reviewers have done their invaluable work of aiding us to assess incoming submissions. David Lawrence and Peter Berkesand at LiU E-Press have given invaluable guidance as well as assistance in setting up the site and the manuscript system. The members of the advisory and editorial boards have together with other enthusiasts given us invaluable encouragement as well as spreading the word to others. Finally, the start up of Valuation Studies was made possible by a grant from The Swedish Research Council.

The comments on an earlier draft from the seminar of the research program ValueS (Science, Technology and Valuation Practices) at Technology and social change improved this manuscript.

\section{References}

Daston, Lorraine, and Peter Galison. 2007. Objectivity. New York: Zone Books.

Dewey, John. 1939. Theory of Valuation. Chicago: University of Chicago Press.

Fourcade, Marion. 2011. "Cents and Sensibility: Economic Valuation and the Nature of 'Nature'." American Journal of Sociology 116 (6): 17211777.

Kjellberg, Hans, Alexandre Mallard, Diane-Laure Arjaliès, Patrik Aspers, Stefan Beljean, Alexandra Bidet, Alberto Corsín, Emmanuel Didier, Marion Fourcade, Susi Geiger, Klaus Hoeyer, Michèle Lamont, Donald MacKenzie, Bill Maurer, Jan Mouritsen, Ebba Sjögren, Kjell Tryggestad, François Vatin, and Steve Woolgar. 2013. "Valuation Studies? Our Collective Two Cents." Valuation Studies 1 (1): 11-30.

Lamont, Michèle. 2009. How Professors Think: Inside the Curious World of Academic Judgment. Cambridge: Harvard University Press.

- 2012. "Toward a Comparative Sociology of Valuation and Evaluation." Annual Review of Sociology 38: 201-221.

Poon, Martha. 2009. "From New Deal Institutions to Capital Markets: Commercial Consumer Risk Scores and the Making of Subprime Mortgage Finance." Accounting, Organizations and Society 34 (5): 654674. 
Stark, David. 2009. The Sense of Dissonance: Accounts of Worth in Economic Life. Princeton: Princeton University Press.

Vatin, François. 2013. "Valuation as Evaluating and Valorizing." Valuation Studies 1 (1): 31-50.

Wallace, W. Timothy, Alan Seigerman, and Morris B. Holbrook. 1993. "The Role of Actors and Actresses in the Success of Films: How Much Is a Movie Star Worth?" Journal of Cultural Economics 17 (1): 1-27.

Claes-Fredrik Helgesson is professor in Technology and Social Change at Linköping University. His research interest concerns in broad terms the intertwining of economic organising, science and technology. The theoretical inspiration comes primarily from social studies of science and technology (STS), while the interest in economic organising, makes his overall orientation located at the conjunction between STS, market studies and economic sociology. He is currently, together with Francis Lee, pursuing a research project called Trials of Value focusing on the multi-faceted valuations entailed when establishing the design of medical experiments.

Fabian Muniesa is researcher at the Center for the Sociology of Innovation at Mines ParisTech. His research contributions are mostly located in the fields of science and technology studies and economic sociology. His work primarily aims at developing a pragmatist, materialist approach to the study of calculation, valuation and organization. His recent and current research topics include the automation of financial markets, the practice of economics, the implementation of performance indicators, the pedagogy of business, and the anthropology of capitalization. 